\title{
A comparison in the quality of care among legally coerced and voluntary clients in outpatient substance abuse treatment programs Brian Perron
}

\author{
Address: Washington University, One Brookings Drive, St. Louis, Missouri 63130, USA \\ from WPA Thematic Conference. Coercive Treatment in Psychiatry: A Comprehensive Review \\ Dresden, Germany. 6-8 June 2007 \\ Published: 19 December 2007 \\ BMC Psychiatry 2007, 7(Suppl I):PI5 doi:10.II86/I47I-244X-7-SI-PI5
}

This abstract is available from: http://www.biomedcentral.com/I47I-244X/7/SI/PI5

(C) 2007 Perron; licensee BioMed Central Ltd.

\section{Background}

Mandating treatment, or legal coercion, in the substance abuse treatment system is a common practice. There has been extensive debate on the ethical issues of this practice. However, very little is known whether the quality of care for persons who are legally coerced differs from persons who attend voluntarily. The purpose of this study is to examine differences in service quality.

\section{Methods}

This study used data from the National Treatment Improvement Evaluation Study (NTIES). The NTIES was a prospective study of the impact of treatment programs on persons in publicly funded substance abuse treatment program. Subjects for this study were from outpatient non-methadone and non-correctional settings $(\mathrm{N}=$ $1,439)$ from 31 different treatment programs. Objective quality of care was measured by the presence of a treatment plan, whether subjects were in agreement with the treatment goals, and the proportion of service needs that were matched. Subjective quality was measured using an indicator of overall treatment satisfaction. The primary analytic strategy was multilevel linear and logistic modeling.

\section{Results}

Approximately $41 \%$ of the subjects were legally coerced to attend substance abuse treatment. No differences were observed in the objective measures of quality of care. However, there were differences in subjective quality of care - legally coerced persons were less likely to be satisfied with their overall treatment experience. Significant variability across treatment programs for all the quality indicators was observed.

\section{Conclusion}

The results revealed differences in the subjective but not objective quality of care among legally coerced and voluntary persons. Because legal coercion is commonly used, it is important to consider different treatment engagement strategies based on legal status. Additional research is also needed in order to understand the variability in quality across treatment programs. 